Marquette University

e-Publications@Marquette

$10-1-2016$

Managing the Tensions at the Intersection of the Triple Bottom Line: A Paradox Theory Approach to Sustainability Management

Lucie K. Ozanne

University of Canterbury

Marcus Phipps

University of Melbourne

Todd Weaver

Point University

Michal Carrington

University of Melbourne

Michael Luchs

College of William and Mary

See next page for additional authors

Published version. Journal of Public Policy \& Marketing, Vol. 35, No. 2 (Fall 2016): 249-261. DOI. (C) 2016, American Marketing Association. Used with permission. 


\section{Authors}

Lucie K. Ozanne, Marcus Phipps, Todd Weaver, Michal Carrington, Michael Luchs, Jesse Callin, Shipra Gupta, Nicholas J. C. Santos, Kristin Scott, and Jerome Williams 


\title{
Managing the Tensions at the Intersection of the Triple Bottom Line: A Paradox Theory Approach to Sustainability Management
}

\author{
Lucie K. Ozanne, Marcus Phipps, Todd Weaver, Michal \\ Carrington, Michael Luchs, Jesse Catlin, Shipra Gupta, \\ Nicholas Santos, Kristin Scott, and Jerome Williams
}

\begin{abstract}
Corporate sustainability management encompasses multiple dimensions: environmental, social, and economic. Companies are increasingly evaluated within the public sphere, and within their own organizations, according to the degree to which they are perceived to simultaneously promote this nexus of virtues. This article seeks to explore the tensions frequently faced by organizations that strive to manage these dimensions and the role of public policy in that pursuit. A multiple-case study approach is utilized in which the authors selected case organizations according to whether they were attempting to manage the three dimensions of sustainability. The authors utilize paradox theory and a typology provided by previous research to understand the nature of the tensions that emerge in the selected case study organizations. They extend this previous work by examining the role of public policy in providing the situational conditions to make these paradoxical tensions salient, and they examine organizational responses to these conditions. Directions for firms, policy makers, and future researchers are provided on the basis of this study's findings.
\end{abstract}

Keywords: triple bottom line, corporate sustainability, paradox theory, environment, social justice

C ompanies are increasingly evaluated both in the public sphere and by organizational stakeholders on the basis of the degree to which they are perceived to be promoting the virtues of "sustainability," yet this is not a straightforward endeavor. As is clearly evident in the variety of the term's definitions, sustainability encompasses multiple dimensions - environmental, social, and economic - sometimes referred to as the "triple bottom line" (e.g., Elkington 2004;

Lucie K. Ozanne is Associate Professor of Marketing, University of Canterbury (e-mail: lucie.ozanne@canterbury.ac.nz). Marcus Phipps is Lecturer of Marketing, University of Melbourne (e-mail: mphipps@unimelb. edu.au). Todd Weaver is Professor of Business, Point University (e-mail: todd.weaver@point.edu). Michal Carrington is Lecturer in Marketing, University of Melbourne (e-mail: michal.carrington@unimelb.edu.au). Michael Luchs is Associate Professor of Marketing, Mason School of Business, College of William \& Mary (e-mail: Michael.Luchs@mason.wm. edu). Jesse Catlin is Assistant Professor of Marketing, California State University, Sacramento (e-mail: jesse.catlin@csus.edu). Shipra Gupta is Assistant Professor of Business Administration, University of Illinois, Springfield (e-mail: shipra.gupta@uis.edu). Nicholas Santos is Assistant Professor of Marketing, College of Business, Marquette University (e-mail: nicholas.santos@marquette.edu). Kristin Scott is Assistant Professor of Marketing and International Business, Minnesota State University, Mankato (e-mail: kristin.scott@mnsu.edu). Jerome Williams is Provost, Rutgers University-Newark (e-mail: jeromew@rutgers.edu). Ronald Paul Hill served as associate editor for this article.
World Commission on Environment and Development 1987). The importance of sustainability as a business issue has grown over the past two decades, as evidenced by a recent global survey of over 2,500 organizations that finds $65 \%$ of companies indicate that sustainability is a top management agenda item (Kiron et al. 2015). Yet many companies struggle to match their strong level of sustainability concern with equally strong actions, given the complex nature of managing many sustainability-related issues (Kiron et al. 2013). Our goal in this research is to help clarify this complexity. Specifically, we draw on paradox theory to elucidate the tensions that exist as organizations strive to manage environmental, social, and economic concerns and the role of public policy in that process. A paradox approach "presumes that tensions are integral to complex systems and that sustainability depends on attending to contradictory yet interwoven demands simultaneously" (Smith and Lewis 2011, p. 397). We note that public policy can foreground paradoxical tensions and make them more salient to organizations. However, we find that an organization's response to these salient tensions can enable it to manage the tensions and achieve sustainability goals in the long run.

Researchers in the field of sustainable production and consumption have pointed out some of the complexity and inherent tensions involved in managing the three dimensions of sustainability (Hahn et al. 2010; Phipps et al. 2013; Van der Byl and Slawinski 2015). Organizations must manage intertemporal 
tensions (Slawinski and Bansal 2015), organizational selfinterest versus societal responsibility (O'Driscoll 2008), and the demands of shareholders versus wider stakeholders (Margolis and Walsh 2003). Similarly, while marketing researchers have noted the importance of corporate social responsibility to consumers (e.g., Sen and Bhattacharya 2001), demonstrating potential compatibility among social, environmental, and economic goals, they have also noted the challenges of pursuing social and environmental goals alongside economic objectives (Mish and Scammon 2010).

Researchers and practitioners have frequently prioritized one dimension over the others, downplaying the dimensions' interdependence (Van der Byl and Slawinski 2015). In particular, practitioners frequently have greater incentives to pursue economic objectives, and public policy can even create barriers to noneconomic pursuits, such as when laws of incorporation assign managers a fiduciary duty to seek the economic best interest of shareholders (Macey 1991). Likewise, research in this area has often been "framed around an instrumental logic ... where managers seek immediate financial gains from their social and environmental investments" (Gao and Bansal 2013, p. 241), thus prioritizing the economic dimension and ignoring tensions that commonly arise.

Research that explores the management of sustainability tends to be conceptual in nature. There is a lack of empirical studies examining how firms effectively manage the intersection of social, environmental, and economic responsibilities (Van der Byl and Slawinski 2015). In addition, Van der Byl and Slawinski (2015) suggest a lack of consistency in how researchers approach tensions in sustainability research; they call for research to delve more deeply into associated tensions, suggesting that "there is a benefit to acknowledging the coexistence of contradictory elements or tensions" (p. 59). This argument suggests the need for an approach to sustainability management that avoids either/or solutions and focuses instead on the opportunities to manage competing sustainability demands simultaneously.

To fully explore competing sustainability demands, research requires "a systems view of organizations as embedded in society and the natural environment," including an examination of public policy (Van der Byl and Slawinski 2015, p. 72). Indeed, recent research has found that social entrepreneurs perceive their organizations' operating contexts to be highly uncertain, with changing government policy being one of the primary sources of that uncertainty (Weerawardena and Sullivan Mort 2012). Although research has explored the impact of public policy on the pursuit of ecological (e.g., Press and Arnould 2009) and social (e.g., Arnould, Plastina, and Ball 2009) objectives in isolation, very little research has explored the impact of policy on the integrated management of the three dimensions of corporate sustainability.

Thus, the purpose of this research is to advance beyond a simple recognition of the inherent complexity of managing corporate sustainability, deepening our understanding of the specific tensions that often emerge in sustainability management, the role of public policy in making these tensions salient, and successful organizational responses to these tensions. The article specifically examines three facets of corporate sustainability: (1) What are the tensions that frequently emerge at the intersection of the triple bottom line? (2) How might the public policy context make these tensions more salient? (3) How do organizations respond effectively to these paradoxical tensions? We pursue these research questions through a multiple-case study methodology examining organizations - across a range of sizes, industries, and locations - that strive to manage the triple bottom line. To help clarify the complexity surrounding sustainable management, we employ paradox theory (Smith and Lewis 2011), which, in contrast to prior perspectives on sustainability management, suggests that the tensions that frequently arise among the goals of the triple bottom line cannot be easily resolved and should be accepted as enduring paradoxes. Nevertheless, by accepting these paradoxical tensions and responding appropriately, firms can potentially achieve a "dynamic equilibrium" that allows them to achieve their economic, social, and environmental goals in the long run.

\section{Literature Review}

The key role of business in the pursuit of sustainability has led to the emergence of the notion of corporate sustainability (Hahn et al. 2015). As defined by Van Marrewijk (2003), corporate sustainability refers to a company's voluntary inclusion of social and environmental concerns in business operations and in interactions with stakeholders. While corporate sustainability expands accountability beyond its traditional financial focus to include environmental and social components (Simpson and Radford 2014), the literature is less clear on how to manage these diverse organizational responsibilities (Van der Byl and Slawinski 2015). Traditional economic responsibilities relate to customer value creation and the financial performance of the organization (Bansal 2005). Firm social responsibilities relate to impacts on society and the well-being of individuals and communities (Elkington 2004); examples of these socially oriented organizational considerations include social equity, community relations, charitable partnerships, workplace ethics, and protection of employee health and safety (Simpson and Radford 2014). A firm's environmental responsibilities focus on its activities relative to the natural environment (Hart 1995) and include activities to reduce the firm's ecological footprint, protect the natural environment, and reduce the use of nonrenewable resources, among others (Bansal 2005).

Scholars have examined corporate sustainability and corporate social responsibility (CSR) from four main vantage points: win-win, trade-off, integrated, and, most recently, paradox (Hahn et al. 2010; Van der Byl and Slawinski 2015). These approaches differ on the relative importance of the three elements and the manner in which these elements can and should be integrated (Angus-Leppan, Benn, and Young 2010). However, the vast majority of extant research, both conceptual and empirical, has adopted a win-win view, which suggests that the three elements of corporate sustainability are harmonious and can be achieved simultaneously (Hahn et al. 2010). Utilizing a win-win approach, also referred to as the business case for CSR (Salzmann, Ionescu-Somers, and Steger 2005), researchers have argued that pursuit of the environmental or social aspects of CSR should result in better financial performance (Porter and Van der Linde 1995). The business case for sustainability has increasingly been utilized to legitimize sustainability strategies (Salzmann, Ionescu-Somers, and Steger 2005); in other words, if sustainability efforts can be shown to offer profits, a business case can be made for their inclusion in firm operations. A wealth of research has also examined 
whether pursuing corporate sustainability or CSR enhances firm financial performance (Kang, Germann, and Grewal 2016; Margolis and Walsh 2003; Orlitzky, Schmidt, and Rynes 2003). Some critics have argued for an alternative approach, maintaining that the win-win approach is too simplistic and that it ignores the complexity and necessary trade-offs, dismisses the inherent tensions, and views sustainability efforts through the lens of profit maximization (Hahn et al. 2010, 2015; Van der Byl and Slawinski 2015).

One such alternative, the trade-off approach, argues that in many situations, the three dimensions of sustainability are in conflict, and thus sustainability can be achieved only if a firm trades off one sustainability dimension in favor of another. For instance, firms may sacrifice short-term financial goals in pursuit of longer-term social goals. Hahn et al. (2010) argue that conflicts and trade-offs in corporate sustainability are the rule rather than the exception, yet they have received relatively limited attention in the literature. These authors develop a framework to illustrate that trade-offs can occur at the individual, organizational, industry, or society level and in the outcome, process, or time dimension of managing corporate sustainability. However, recent research has challenged the trade-off approach, finding that firms, when pressed to choose, will typically favor financial goals (Slawinski and Bansal 2015) and suggesting that, in practice, the trade-off approach favors profit maximization. Furthermore, while traditional management theories have often depicted organizational phenomena in terms of discrete opposing categories, such as autonomy-control, exploration-exploitation, globallocal, centralized-decentralized, and profit-social responsibility (Denison, Hooijberg, and Quinn 1995; Smith and Lewis 2011), more recent scholarship has explored how organizations can attend to these competing goals simultaneously rather than seeing them as either/or choices (O'Driscoll 2008; Smith and Lewis 2011). In addition, Lewis (2000) argues that as the business world becomes increasingly competitive, globally focused, and fast paced, the tensions among these disparate goals become increasingly salient to organizations. In response to these challenges to earlier approaches, the integrated and paradoxical approaches have been developed.

The integrated approach assumes that the three dimensions of corporate sustainability are interrelated and part of an embedded organizational system. "No individual elements can be isolated, and a change in one of these elements will result in changes throughout the tightly woven interconnected system" (Gao and Bansal 2013, p. 242). While the win-win approach has, in practice, tended to favor the economic dimension over the social or environmental dimensions, the integrated approach seeks to bring the elements together without favoring one element over the others (Hahn et al. 2015; Van der Byl and Slawinski 2015). For instance, Hahn and Figge (2011) suggest an inclusive notion of profitability that goes beyond economic efficiency as the instrumental focus. "Rather, it readjusts profitability to address all different forms of capital-economic, environmental, and socialwithout any systematic a priori predominance of any of the capital forms" (p. 338). Yet despite considerable research employing the integrated approach, there still exists a "lack of a systematic understanding of the nature of these relationships" (Hahn et al. 2015, p. 298) because much of the research is conceptual in nature (Van der Byl and Slawinski 2015). In addition, research that takes an integrative approach has offered relatively little practical guidance on how to address the tensions in corporate sustainability (Van der Byl and Slawinski 2015).

In light of these issues, a paradoxical approach has been developed to build on the integrative approach and to explore the inherent tensions in corporate attempts to manage sustainability. Under this approach, the nature of tensions is viewed as paradoxical. Paradoxes refer to contradictory yet interrelated demands that persist over time and require acceptance and continuous efforts to manage them (Smith and Lewis 2011). These contradictory elements seem logical or desirable in isolation but inconsistent when juxtaposed, such as the strategic demands of exploration and exploitation (Smith, Binns, and Tushman 2010). According to the paradoxical approach, firms face multiple paradoxical tensions that may be better addressed as interrelated contradictions rather than win-wins or trade-offs (Van der Byl and Slawinski 2015). For instance, the pursuit of both profit maximization and minimization of the firm's ecological footprint can create contradictions. Profit maximization may suggest outsourcing to distant locations to lower costs, while the firm's ecological footprint may emphasize using local suppliers to reduce carbon miles. Yet a strong relationship with local suppliers could also enhance profit through creating closer links to the supply chain and an opportunity to emphasize the quality of local materials, exemplifying the interrelationship between these dimensions.

Smith and Lewis (2011) identify four categories of paradoxical tensions-belonging, performing, organizing, and learning - that represent core activities of organizations (Lewis 2000; Luscher and Lewis 2008; Smith and Lewis 2011):

- Belonging tensions (Smith and Lewis 2011) arise because organizational actors strive for both self-expression and group affiliation (Lewis 2000). These issues of identity foster tensions in the areas of organizational culture, values, roles, and membership (Smith and Lewis 2011). As Luscher, Lewis, and Ingram (2006) explain, belonging tensions manifest as actors seek to identify themselves in relation to the organization and its varied and fluctuating groups. For instance, Wright, Nyberg, and Grant (2012) investigate identity tensions among corporate sustainability managers as they struggle to reconcile their sustainability identity and their organizational identification.

- Performing tensions arise from the plurality of stakeholders in the organization's operations and result in competing strategies and goals (Smith and Lewis 2011). Performing tensions are also present in the manner in which organizational performance is measured. In terms of corporate sustainability, financial goals are typically quantitative in nature, whereas social and environmental goals may be more subjective in nature, making measurement difficult. For instance, Delmas and Doctori Blass (2010) argue that financial performance indicators are well defined and structured, whereas environmental performance indicators are quite heterogeneous and nonstandardized.

- Organizing tensions arise as complex organizational systems create competing designs, structures, processes, and practices to achieve desired outcomes (Smith and Lewis 2011). Compared with paradoxes of performing and belonging, paradoxes of organizing operate at a more macro level (Luscher and Lewis 2008 ) and often manifest during periods or organizational restructuring or change (Jarzabkowski, Lê, and Van de Ven 2013). In marketing, organizing tensions relate to the tension between relational and transactional marketing, mass and oneto-one communication, globalization and localization, strategic 
planning and improvisation (O'Driscoll 2008). For instance, Andriopoulos and Lewis (2009) find that highly innovative firms struggle with the tension of customer orientation, particularly the need to be both tightly and loosely coupled to clients. Likewise, through a commitment to multiple goals, firms pursuing the triple bottom line may face inconsistent human resources practices (Smith, Gonin, and Besharov 2013).

- Learning tensions manifest, as Lewis (2000) explains, when organizational beliefs and assumptions fail to keep pace with contextual change. For instance, firms that hold fast to core competencies may hinder attempts to innovate and may miss environmental opportunities as these capacities become obsolete. Learning tensions also emerge in the juxtaposition of multiple time horizons; as firms seek growth in the long term, they also need stability and certainty in the short term (Smith, Gonin, and Besharov 2013). DeFillippi (2009) discusses learning tensions as those involved in creative efforts struggle to develop the skills to both create content as well as utilize consumer-generated content for promotional materials.

In light of these tensions, the paradoxical approach moves beyond simple integration or trade-offs of sustainability dimensions to examine the complexity that arises when contradictory yet interrelated elements are considered simultaneously (Van der Byl and Slawinski 2015). Smith and Lewis (2011) use paradox theory to develop a dynamic framework that "supports the opposing forces and harnesses the constant tension between them, enabling the system to not only survive but continuously improve" (p. 386). They argue that organizational tensions remain latent until environmental factors of scarcity, plurality, and change highlight the contradictory nature of the tensions, making them salient to organizational actors. Conditions of scarcity involve constraints due to limitations on the resources available to the organization, such as time, labor, and capital. Plurality represents conditions of uncertainty as to organizational goals and the strategies necessary to achieve them. Finally, change means shifts in contextual conditions, which force the organization to adapt. Often, conditions of change highlight the tension between long-term and short-term results.

A paradox approach argues that long-term success requires continuous efforts to meet multiple demands, not by trading off or prioritizing one goal over others but by a dynamic process of splitting and synthesis (Smith and Lewis 2011). By splitting a paradox, actors focus on each pole of the paradox to accentuate its distinct value (Poole and Van de Ven 1989), and this process facilitates the development of short-term strategies to address the most pressing or valuable of the paradoxical objectives. However, synthesis means that this short-term splitting process is repeated cyclically, with new priorities emerging in each cycle (Smith and Lewis 2011). In the long run, a dynamic equilibrium emerges, which involves "purposeful iterations between alternatives in order to ensure simultaneous attention to them over time" (Smith and Lewis 2011, p. 392). Thus, in the case of sustainability, paradox theory suggests that organizations can attend to the competing demands of the triple bottom line to varying degrees over time, thereby reaching a dynamic equilibrium to effectively manage all three objectives. Doing so promotes a virtuous cycle of tension and resolution as the firm responds dynamically to the changing and competing demands of sustainability management (Smith and Lewis 2011).

While this approach has only recently emerged, and research is still nascent, it has been argued that, compared with previous research, it provides a more robust method for understanding the tensions inherent in managing corporate sustainability (Hahn et al. 2015; Van der Byl and Slawinski 2015). For instance, Scherer, Palazzo, and Seidl (2013) explore firms' attempts to maintain legitimacy in complex environments where sustainable development is addressed and argue that those who simultaneously employ multiple legitimacy strategies are better able to respond to contradictory legitimacy demands. Likewise, Slawinski and Bansal (2015) examine intertemporal aspects of corporate sustainability and find that those firms who have a short-term orientation frame climate change as an economic problem requiring firm solutions, whereas those who demonstrate "temporal ambidexterity by juxtaposing time" horizons see the complexity of the issue and identify collaboration as key to addressing the issue (p. 546). Next, we outline our case study approach to investigate the paradoxes within the triple bottom line.

\section{Research Methods}

The primary purposes of this exploratory research are to empirically observe the tensions that exist at the intersection of the triple bottom line, to illuminate the role of public policy in accentuating these tensions, and to identify successful organizational responses to these tensions. We employed a multiple-case study approach to meet these aims. This approach permits a replication logic, in which the cases are treated as a series of independent experiments that confirm or disconfirm emerging conceptual insights (Eisenhardt and Graebner 2007; Yin 2013). Multiple cases also "enable a broader exploration of research questions" (Eisenhardt and Graebner 2007, p. 27). Because we were interested in the tensions involved in managing sustainability, we used purposeful sampling (Eisenhardt 1989; Patton 1990) to select case organizations that were attempting to manage the three dimensions of sustainability rather than organizations that were necessarily successful or exemplary in their approach. Thus, we selected organizations that were dedicated to pursuing all three objectives of the triple bottom line.

For this project, each author collected data from one to two organizations, for a total of 19 cases. In order to facilitate and standardize the collection of case data, we created and refined a data collection template that is based on relevant dimensions identified from the literature (Hansmann, Mieg, and Frischknecht 2012; Menguc and Ozanne 2005; Scott et al. 2011). We collected information across a range of issues, including environmental and social issues managed, role of stakeholders, public policies that support or impede environmental and social initiatives, and tensions in managing issues, among others. The goal for each case was to provide a concise but comprehensive overview of the company's operations, emphasizing those aspects pertaining to issues of sustainability and public policy. We used a variety of secondary sources to collect data on case organizations, including annual and corporate social responsibility reports, organizational websites, press articles, and materials provided by the organizations. When needed, interviews were conducted with members of the organization in order to clarify and provide more in-depth data ( $n=9$ out of 19 final cases). We utilized over 2,352 pages of secondary documents, in addition to interview transcripts.

We sought diversity in organizational location, size, and business type in order to broaden the exploration of the research questions and to satisfy Patton's (1990) criterion of maximum variation (see Table 1). Each case was authored 


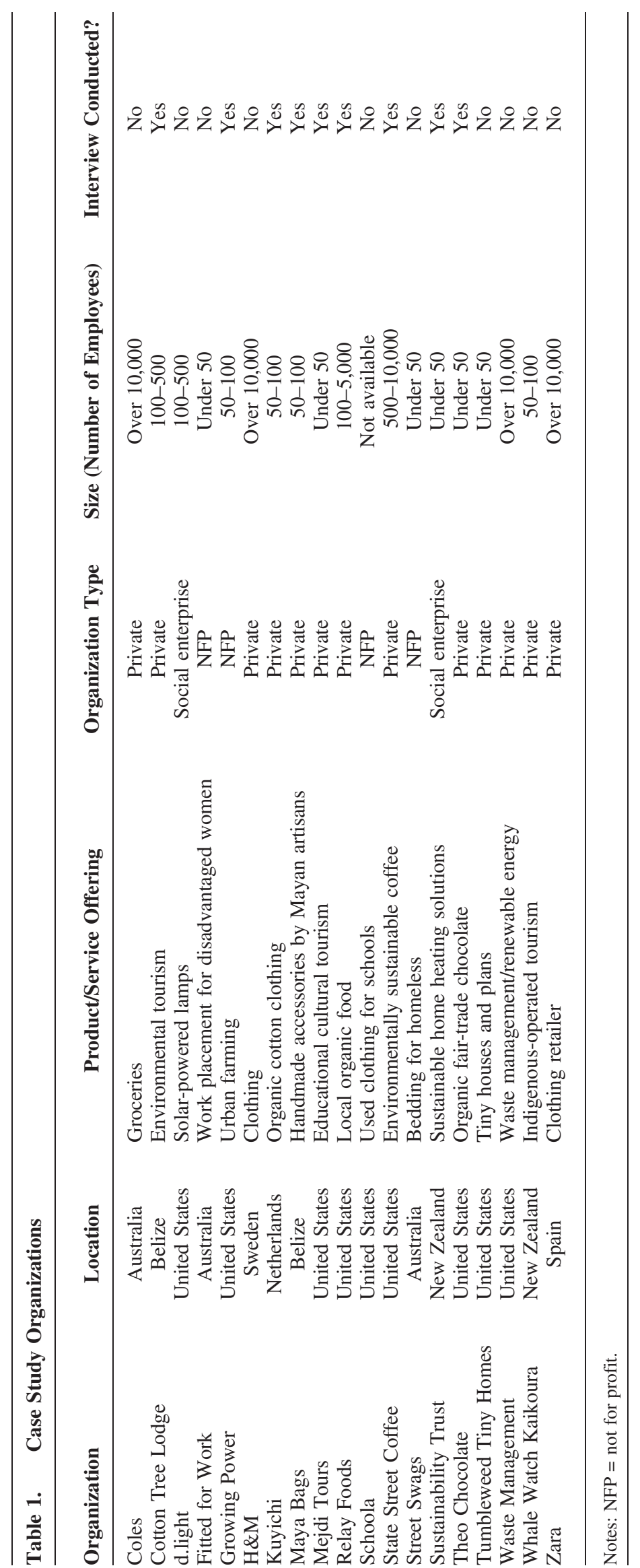


individually and provided to the rest of the authors for analysis. According to Eisenhardt (1989), these write-ups are often simply pure description, but they are central to the generation of insight because they help researchers cope with the enormous volume of data. To facilitate within-case analysis (Eisenhardt 1989), cases were also presented verbally by the case author for discussion during a group analysis session. This approach allowed all authors to become familiar with each case as a stand-alone entity. From the within-case analysis, we identified categories of data that then enabled the identification of cross-case patterns and differences (Eisenhardt 1989). The cross-case analysis followed Yin's (2013) explanation building approach, whereby explanation emerges from an iterative approach of initial theoretical statement, comparing findings of an initial case, revising statement, comparing details of the case, revising, and comparing with other additional cases. From this within-case and across-case analysis, we collectively distilled a set of key themes, which we discuss in the following section.

\section{Findings}

A paradox theory approach suggests that we move away from considering organizational tensions as either/or decisions and instead use a both/and approach (O’Driscoll 2008). Framing sustainability tensions as paradoxes allows researchers to explore the process by which firms manage these tensions as they arise and interact (Jay 2013). First, we outline the inherent strategic and tactical tensions that exist for triple-bottom-line organizations by drawing from Smith and Lewis's (2011) four tensions of belonging, performing, organizing, and learning (Theme 1). Second, we demonstrate how public policy frameworks can make these tensions salient by creating conditions of scarcity, change, and plurality (Theme 2). Finally, we examine successful organizational responses to these paradoxical tensions (Theme 3).

\section{Theme 1: Tensions That Emerge at the Intersection of Managing the Triple Bottom Line}

\section{Belonging Tensions}

Belonging tensions refer to identity issues in the need to appease multiple stakeholders. In organizations that pursue the triple bottom line, belonging tensions emerge as organizational actors face questions of which of the three dimensions they are most aligned with and how they can manage divergent identity expectations (Smith, Gonin, and Besharov 2013). Although this type of tension can certainly be felt at the individual level, our case data indicate that it also exists at the group level, as organizational stakeholders find themselves torn between competing objectives and in conflict with other stakeholders in terms of priorities.

One such example is d.light, a global social enterprise that delivers affordable solar-power solutions for people in the developing world who lack access to reliable energy. The company's affordably produced solar lamps and home solarpower systems provide a healthier and more environmentally friendly source of light to the kerosene lamp commonly used in developing regions. At the same time, d.light articulates a clear commitment to a private-enterprise approach. As noted by an official from the World Bank Group, "The only way to [reach the energy-poor] in a sustainable way is for everyone along the value chain to make money" (Lavelle 2015). While this for-profit approach aligned with the identity of the venture capitalists who funded the enterprise, it concerned other stakeholders who identified with the organization's social mission. For instance, d.light president Ned Tozun noted that the d.light's engineers were more "passionate about building a product that millions of people will use" than about the economic goals of the organization (Farr 2013).

This belonging tension also surfaced as d.light expanded its operations into China. As a developing nation, China prioritizes economic development over environmental sustainability and social justice (Zhang and Wen 2008). Tozun noted that the concept of a social business seemed strange to Chinese people. Potential investors and employees in China assumed that the dimensions of the triple bottom line could not be pursued simultaneously by one organization, so they categorized d.light as either a charity or an unsuccessful business, neither of which was very appealing (World Economic Forum 2016). For additional examples of belonging tensions from our cases, see Table 2.

\section{Performing Tensions}

Performing tensions involve the need to meet competing strategies and goals. Almost all of our case organizations faced performing tensions. Relay Foods is a for-profit online grocer that specializes in locally sourced and organic foods. The organization seeks to ensure that its social goals of delivering healthy, locally grown organic food are intertwined with its environmental goals as much as possible. For instance, to minimize its environmental footprint, the company allows consumers to choose a convenient pick-up location that coincides with their normal commute. Warehouses store food that comes in from local farms, and when consumers shop for the food online, they have access to information about where the products come from as well as nutritional information about the products.

Nevertheless, these goals are sometimes at odds. For instance, healthier (organic) food is often more expensive, making it less affordable for lower-income market segments. In addition, Relay also faces the challenge of promoting its environmental efforts, which often add to costs, while promoting its service and products to lower-income families. Thus, in order to grow awareness among this segment, company representatives explain, "We reach out to low-income schools to provide education on healthy eating and cooking." Executives at Relay Foods believe that the low-income market can benefit from their locally sourced organic goods; yet they recognize that their offerings, while healthier, are higher priced than those of an average grocery store.

Furthermore, Relay also struggles with verifying aspects of environmental performance. Many of its local growers "can't afford formal organic certification, [so] we will verify their practices and communicate and prioritize these suppliers on our website." Although not verified by a third party, Relay employees try to "guide purchases" toward what they believe to be more environmentally friendly practices.

\section{Organizing Tensions}

Organizing tensions refer to complexities in relation to designs, structures, processes, and practices. Sustainability Trust is a registered charity and social enterprise with over 30 
Table 2. Paradoxical Tensions in Case Study Organizations

\begin{tabular}{|c|c|c|}
\hline Tension & Definition & Examples \\
\hline Belonging & $\begin{array}{l}\text { Arises as organizational actors strive for } \\
\text { both self-expression and group } \\
\text { affiliationa }\end{array}$ & $\begin{array}{l}\text { - d.light: private enterprise approach vs. environmental and social identity } \\
\text { - Growing Power: acceptance of aid from large corporates at odds with social } \\
\text { justice goals } \\
\text { - Sustainability Trust: question of when to promote social/environmental } \\
\text { missions, business acumen, or both; need to assess new initiatives against } \\
\text { organizational mission } \\
\text { - Tumbleweed Tiny Homes: divergent identity expectations of key organizational } \\
\text { actors } \\
\text { - Zara: fast-fashion business model at odds with stated goal of sustainable } \\
\text { development }\end{array}$ \\
\hline Performing & $\begin{array}{l}\text { Arises from the need to satisfy multiple } \\
\text { stakeholders in the organization's } \\
\text { operations and result in competing } \\
\text { strategies and goals }\end{array}$ & $\begin{array}{l}\text { - Coles: desire to support local producers at odds with environmental goals } \\
\text { - Cotton Tree Lodge: prioritization of local employees over financial performance } \\
\text { - H\&M and Kuyichi: desire to provide living wage for workers vs. financial } \\
\text { performance } \\
\text { - Maya Bags: use of environmentally sustainable materials vs. financial } \\
\text { performance; empowering female workers vs. financial performance } \\
\text { - Mejdi Tours: promoting social and cultural understanding yet utilizing air travel } \\
\text { with high carbon footprint } \\
\text { - Relay Foods: high price of local organic food vs. commitment to serve low- } \\
\text { income families; verifying environmental performance of suppliers }\end{array}$ \\
\hline Organizing & $\begin{array}{l}\text { Arises as complex organizational } \\
\text { systems create competing designs, } \\
\text { structures, processes, and practices to } \\
\text { achieve desired outcomes }{ }^{b}\end{array}$ & $\begin{array}{l}\text { - Coles: control vs. flexibility in dealing with supply-chain members } \\
\text { - Fitted for Work: hiring practices } \\
\text { - Relay Foods: positioning convenience items vs. local organic specialty items; } \\
\text { corporate policy of substituting local organic with organic products from } \\
\text { nonlocal sources } \\
\text { - State Street Coffee: empowerment vs. direction in supply chain } \\
\text { - Street Swags: collaborative approach vs. need to compete against new entrant } \\
\text { - Sustainability Trust: need to work with organizations it also competes against }\end{array}$ \\
\hline Learning & $\begin{array}{l}\text { Arises from processes of innovation and } \\
\text { transformation that reveal tensions } \\
\text { between old and new practices }\end{array}$ & $\begin{array}{l}\text { - d.light: development of most effective supply chain } \\
\text { - Kuyichi: development of environmentally sound technologies, may impact } \\
\text { profitability } \\
\text { - Mejdi Tours: short-term quality vs. long-term ability to influence more tourists } \\
\text { - Tumbleweed Tiny Homes: adapting houses as recreational vehicles to meet } \\
\text { regulations in short term } \\
\text { - Whale Watch Kaikoura: need to adapt to increasing understanding of impact of } \\
\text { tourism on whales }\end{array}$ \\
\hline
\end{tabular}

aDefinition derived from Lewis (2000).

bDefinition derived from Smith and Lewis (2011).

staff members, who deliver a mix of government-subsidized and income-generating projects around the Wellington region in New Zealand. The organization's social mission is to help people who are on a government benefit and/or have health issues that are exacerbated by living in houses that have inadequate insulation or heating, a common problem in older New Zealand homes. In order to generate revenues, the social enterprise specializes in providing green technology for higher-income households.

Sustainability Trust's organizing tensions emerged from the need to service two contrasting target segments. With the highincome households, the organization's goal is to promote efficiency or reduction in resource use (e.g., water, energy). However, according to a Sustainability Trust representative, low-income households, in the vast majority of cases, "are low users of energy and we need to be encouraging them to consume more." For instance, during the winter months, many households heat only one room and all household members sleep together in that room. Many houses also lack proper ventilation and lose heat through single-glazed windows. This practice increases the transmission rates of a range of infectious diseases (Bridges 2013). These households are also crowded both in terms of the size of the house relative to the number of people living in it and in terms of too many people crowding into a single room to sleep. Thus, these households should be consuming more in terms of both the size of the house and energy use. The Sustainability Trust is tasked with creating various practices to meet these competing goals and often struggles to find staff with the relevant skill sets.

\section{Learning Tensions}

Learning tensions relate to the need for organizations to keep pace with contextual change. For example, d.light's initial 
distribution strategy was to stock its solar lamps in retailers who carried flashlights and other portable lighting. However, d.light quickly learned that different countries held their own unique challenges in terms of distribution, including widely dispersed customers and different shopping behaviors that often limited the effectiveness of traditional, retailer-based distribution channels. These idiosyncratic distribution challenges forced d.light to be flexible and to adopt a wide variety of distribution models, including selling through importers, distributors, retailers, and "rural entrepreneurs," small-scale independent resellers of d.light lamps. If the company had taken a charitybased approach instead of seeking economic return, it would have been able to distribute its lamps (free of charge) through the wellestablished aid networks that exist in most of these developing countries, freeing d.light from this tension between social and environmental impact and economic return.

Learning tensions were also salient for d.light in human resource practices. In order to enhance profitability and to maintain the control the organization enjoyed when it was smaller, the company initially chose not to install local senior executives. However, over time, the leadership of the organization realized that this practice was impeding its growth and therefore its social and environmental impact (World Economic Forum 2016). Eventually, the organization found that decentralizing and hiring local executives was key to reaching less-developed countries like China and India, even though it increased overhead costs and reduced profitability.

Thus, our case data illustrate the paradoxical tensions that exist at the nexus of the triple bottom line. As our case organizations attempted to pursue social, environmental, and economic sustainability, they encountered persistent and contradictory demands that were difficult to reconcile. Smith and Lewis's (2011) four tensions of belonging, performing, organizing, and learning enabled us to explore these tensions at both individual and strategic levels. In the following section, we turn to an analysis of public policy and how these tensions can become more apparent within certain policy frameworks.

\section{Theme 2: The Role of Public Policy in Making Salient the Tensions in Managing the Triple Bottom Line}

Smith and Lewis (2011) propose that contextual conditionsscarcity, change, and plurality — render latent tensions salient. Our cases demonstrate that public policy can create these conditions and foreground the tensions between triple-bottomline objectives.

First, existing policy structures can create conditions of scarcity. Relay Foods has a social mission to make its online groceries available to lower-income markets. Specifically, Relay Foods wants to provide families who use government assistance (e.g., food stamps; electronic benefit transfer; Women, Infants, and Children program) with access to local and organically farmed goods. However, the company's opportunities to achieve this goal are limited due to the nature of the legislative framework. Because online grocers are not legally defined as grocery stores, the law prohibits food stamps from being used with organizations such as Relay Foods. These conditions of scarcity prevent lower-income families from having access to convenient local and organic groceries.
Second, policy structures can also create or exacerbate conditions of change. Street Swags (www.streetswags.org) is a not-for-profit, Australian-based organization that produces and distributes swags (waterproof canvas sacks for sleeping in that have a built-in foam mattress and are easy to transport) to the homeless. As a not-for-profit social enterprise, the organization provides essential shelter to assist the homeless to stay safe on the streets.

Conditions of change emerged for Street Swags when homelessness policies in Australia shifted. Street Swags's approach was originally aligned with the Australian government policy directive aimed at "managing homelessness with harm minimisation responses" (Parsell, Jones, and Head 2013, p. 190). The homelessness policy direction in Australia, however, has recently taken a dramatic shift to a dual focus of (1) prevention and early intervention and (2) purposeful intervention to assist people in exiting permanently from homelessness (Parsell, Jones, and Head 2013). This refocusing of government policy and financial support has left Street Swags in a position of financial vulnerability. Policy conditions of change have exacerbated both belonging and performing tensions for the organization.

The Street Swags operating model relies heavily on corporations, government, and the public to donate funds and volunteer labor and resources to enable the manufacture and distribution of the street swags. Donations and government grants cover the costs of the raw materials and transport. Street Swags then draws on volunteer and government-funded programs to manufacture the swags at no cost to the organization. The swags are sewn at a number of prisons across Australia through volunteer, rehabilitation, and training programs.

The swags provide shelter, comfort, and safety to people while they are homeless, but they do not provide a permanent solution for homelessness. Thus, the previous policy context, with its directive of managing homelessness, supported Street Swags's focus and operating model. The dramatic change in Australian government homelessness policy toward a focus on intervention and prevention-that is, finding permanent housing solutions and preventing people from living on the streets in the first place - exposes Street Swags's dependency on government resources and reveals the vulnerability of the organization when changes in policy restrict access to these resources. In this instance, Street Swags's focus on homelessness management no longer aligns with the changed government policy focus on homelessness prevention.

Finally, policy structures can create conditions of plurality. For example, in addition to selling simple and affordable solar lamps, d.light also distributes more expensive solar home systems that can power multiple devices, similar to ongrid electricity. However, these systems are difficult for bottom-of-pyramid consumers to purchase outright, and many of these customers do not have access to credit. As a result, d.light sought a means for consumers to "pay as they go," thereby creating revenues to support profitability while also making a social and environmental impact. However, d.light faces a patchwork of public policies regulating payment mechanisms in the developing countries it is attempting to serve. In Africa, mobile phones provide an excellent means of making monthly payments for solar home systems, but in India, such mobile payments are restricted by local regulations (Chhabra 2014). This policy context has created 
learning and performing tensions for d.light, forcing them to innovate additional means of ongoing payments to suit the developing nations they serve.

Another organization that has encountered plurality challenges is Sustainability Trust. The Warm-Up New Zealand government program provides grants that cover up to $60 \%$ of the cost of insulation installed in low-income households. This policy undoubtedly assists Sustainability Trust to improve well-being and environmental sustainability by making homes warmer, healthier, and more energy efficient. Loopholes in the policy, however, have had unintended consequences that are detrimental to the work of the trust. First, although homeowners or landlords are intended to pay for the remaining cost of the insulation after the subsidy, some for-profit companies (with other, higher-margin revenue streams) offer the insulation completely free as a loss leader. In order to be competitive, Sustainability Trust must also offer the insulation for free and absorb the unsubsidized $40 \%$ of the cost, which inhibits the organization's ability to provide other charitable programs. Furthermore, although the policy was intended to benefit lower-income households, many of these households are made up of renters, so the policy has economically indirectly benefited landlords, many of whom would not qualify for public assistance. Thus, the policy that was intended to facilitate public assistance to underprivileged households has instead resulted in conditions of plurality for them and the organization attempting to serve them, accentuating performing and organizing tensions.

When it comes to energy policy in the developing world, d.light also faces plurality. In order to make energy more affordable for consumers, some countries subsidize fossil fuels. In addition, countries may erect trade barriers to foreign-made goods like those d.light attempts to import. According to d.light CEO Don Tice, "Many developing world governments continue to subsidize low quality, unhealthy and environmentally damaging fossil fuels that power kerosene lanterns and diesel generators, while many also erect trade barriers against renewables like solar power that threaten entrenched energy interests" (World Economic Forum 2016). In this case, plurality highlights performing tensions between profitability goals and social and environmental objectives. Plurality could also exacerbate belonging tensions for d.light: profit-oriented investors might favor markets with fewer regulatory barriers, whereas more altruistic stakeholders might prioritize markets where the need for solar lighting is greatest.

Our case analysis illustrates how public policy can make paradoxical tensions salient for organizations pursuing the triple bottom line. Policy can create conditions of scarcity, change, and plurality, thereby increasing the salience of the tensions.

\section{Theme 3: Organizational Response to Paradoxical Tensions}

The previous section discusses how tensions can be made more salient by policy conditions. When this happens, organizations face a decision of how to respond. Will they trade off between the competing objectives, prioritizing one over others? Will they ignore the tension and pursue a win-win strategy? Our case analysis indicates that organizations that have been successful in achieving triple-bottom-line results have employed the dynamic equilibrium response suggested by paradox theory. In other words, these organizations have made compromises (similar to the trade-off approach) in the short term in order to achieve their sustainability objectives in the long term. Paradoxically, we observe that the same policy conditions that made tensions salient can thus spur organizational innovation in response, creating conditions of abundance (vs. scarcity), stability (vs. change), and certainty (vs. plurality). These conditions reduce tensions and enable firms to find equilibrium among the competing demands of the triple bottom line, pursuing them simultaneously rather than trading off or prioritizing one over others.

\section{Organizational Responses to Scarcity}

As discussed previously, public policy relating to food assistance has created a context of scarcity that enhances paradoxical tensions for Relay Foods. In response to these tensions, Relay could have adopted a trade-off approach and focused on wealthier consumers, prioritizing profits over people. Instead, the firm made short-term investments in R\&D to improve productivity and reduce costs, enabling it to offer more affordable prices to consumers who require food assistance. It also invested in free educational programs to reach this market and educate the consumers on healthy eating. Furthermore, the long-term benefits of these activities are not limited to less-wealthy consumers; all Relay's customers can now afford to buy more of their healthy, organic produce, and Relay can afford to pay higher prices to its local suppliers. Finally, as the business has expanded, the positive environmental impact has increased as well, with a higher percentage of Relay's customers' food purchases now coming from local, sustainable agriculture. Thus, while these decisions reduced short-term profits, the long-term outcome has been more social and environmental impact and economic growth for the business. In that way, the firm's organizational response to scarcity has created conditions of abundance, with lower overhead making its business appealing to more customers and suppliers.

\section{Organizational Responses to Change}

Change - as a contextual factor - can work to transform previously latent tensions into salient concerns (Smith and Lewis 2011). Our study shows that shifts in policy structures can be the source of this change and that this change can create tensions that necessitate flexibility, evolution, and innovation. The Street Swags social initiative exemplifies this scenario. When government policy change exposed tensions between social initiatives and economic viability, it triggered innovation within the organization and a shift in the initiative's operation in parallel with the shift in homelessness policy. Street Swag expanded its operations to include an interventional approach to take people off the streets permanently by providing small cabins that fit in backyards. The labor to construct the cabins is government funded, with youth workers receiving wages and training. Street Swags aims to sell the small cabins to the public and to organizations to place in their yards, and later to offer the cabins to homeless people at affordable rates. In contrast to the swags, the cabins are a more permanent solution for shelter and housing (Gartry 2015). In addition to providing a permanent homelessness solution, the cabins have generated a profit that is to be reinvested to increase production and to provide intensive 
support and training for homeless people. Thus, the change in homelessness policy and the resulting exposure of tensions within the Street Swags operating model has driven significant evolution of Street Swags's offer, concept, and operation, providing stability to the organization and allowing it to achieve economic, environmental, and social results simultaneously.

\section{Organizational Responses to Plurality}

For d.light, the policy context of plurality has spurred innovation in the area of payment mechanisms for its solar home systems. In addition to mobile payments, the organization developed new payment forms, including top-up cards, microloans, savings groups, and other means of payas-you-go payment. In the short term, this effort required greater investment in personnel and systems, hurting financial results. However, in the long term, this organizational response has paradoxically created an abundance of markets and customers that d.light is able to serve profitably. It has also created a type of certainty in that regardless of local policy relating to payment, d.light has confidence that one of its payment options will be suitable to the policy context. This flexibility has enabled the firm to profitably introduce its products into more needy areas, and the company has now had a positive impact on over 50 million bottom-of-pyramid consumers (d.light 2016).

\section{Conclusions}

This article has sought to highlight the tensions within the pursuit of the triple bottom line and to demonstrate to policy makers and practitioners the inherent challenges within these often competing concerns. It has also sought to illuminate the role of policy in making these tensions salient and to explore organizational responses to these tensions. To achieve these goals, we adopted Smith and Lewis's (2011) paradox lens, an approach that has been minimally utilized in marketing scholarship (O'Driscoll 2008), to explicate the tensions involved in the pursuit of the triple bottom line and to understand how policy interacts with these tensions. This article has made three key contributions: (1) outlining the belonging, performing, organizing, and learning tensions that emerge at the intersection of the triple bottom line; (2) illustrating how the public policy environment makes these tensions salient by creating conditions of scarcity, change, and plurality; and (3) illustrating how organizational responses to these tensions can create a dynamic equilibrium that balances the demands of the triple bottom line over time, creating conditions of abundance, stability, and certainty.

First, Theme 1 outlines the paradoxical tensions that make triple-bottom-line firms unique and highly susceptible to such tensions given their commitment to multiple institutional logics (Jay 2013). It is through identifying and acknowledging these tensions that this research seeks to move beyond the limitations of win-win, trade-off, and integrated approaches. For triple-bottom-line firms operating within these contexts, acknowledgment of tensions enables organizational actors to understand and accept that such tensions can and should coexist, and thus it enables pursuit of potential strategies for managing the tensions (Hahn et al. 2015; Smith and Lewis 2011). Organizational scholarship has typically sought to reconcile corporate social initiatives with seemingly incompatible economic logic (Margolis and Walsh 2003). The advantage of the paradox lens is that it highlights opportunities to identify and manage the paradoxes of firms managing across the triple bottom line, providing opportunities for innovation (Hahn et al. 2015). In contrast to approaches that suggest that organizations must prioritize one or more goals over others and accept poorer performance on lower-priority goals, the paradox approach suggests that organizations should accept the existence of paradoxical tensions and manage them effectively (Smith and Lewis 2011).

Policy makers need to recognize that many firms operating at the intersection of the triple bottom line face the learning tension of isomorphic versus structural and technological change identified by Hahn et al. (2015): "the tension to comply with institutional pressures and established practices and the call to act as innovators for more sustainable business practices" (p. 28). As these firms strive to develop products and services that are more sustainable, they confront isomorphic pressures that resist change and stabilize extant practices, with potential change coming at the expense of gaining institutional disapproval and losing legitimacy as these firms challenge established business practice. For example, as Tumbleweed Tiny Homes develops more sustainable housing options, the firm confronts well-established and institutionalized practices, such as zoning policies, building practices, and consumer preferences for larger homes, which threaten its ability to establish legitimacy in the marketplace. Policy makers need to recognize the "education and movement building" efforts of firms, like Tumbleweed Tiny Homes, that seek to challenge established practices and institutional pressures and support them through mixed-funding models and varied approaches to measuring their success (Jay 2013, p. 157).

Our study indicates that public policy plays an important role in making paradoxical tensions more salient to organizations pursuing the triple bottom line. Theme 2 identifies how public policy can create contextual conditions of scarcity, change, and plurality that bring latent organizational tensions to the foreground. Public policy makers need to recognize that some contexts are more prone to producing paradoxical tensions than others (Jarzabkowski, Lê, and Van de Van 2013) and to acknowledge the potential for policy to make these tensions more salient. Future research could identify specific types of policy initiatives or frameworks that tend to foreground tensions of belonging, performing, organizing, and learning. At the same time, we have noted how salient tensions can spur beneficial organizational responses (as discussed in the next paragraph with Theme 3), so future research could explore the policy contexts that give firms the flexibility to innovate in response to the tensions inherent in sustainability management. Future research could also explore whether firm actors recognize and accept the existence of tensions arising from policy frameworks and whether recognition and organizational sense-making (Jay 2013) spurs creative potential or results in organizational "stuckness," wherein actors become trapped by the contradictions posed by paradoxical tensions (Jay 2013, p. 154).

Finally, Theme 3 illustrates the "dynamic equilibrium model" (Smith and Lewis 2011). We find that successful 
organizations intentionally cycle among the competing goals of the triple bottom line so that, over time, competing tensions can be attended to and pursued effectively. For instance, pressing short-term social needs might require a shift of organizational resources away from economic and social goals, but only until those other needs become more pressing. This dynamic equilibrium strategy has enabled organizations to reduce salient tensions and spur opportunities for innovation that include reaching new markets, developing new products, and adopting new forms of payment, among others. For example, Mejdi Tours is currently prioritizing social goals over environmental ones because the firm must use carbon-intensive air travel to achieve its social mission. However, this is not a static, long-term strategy; Mejdi Tours has adopted an innovative means of mitigating its environmental impact by purchasing carbon offsets, and its expressed hope is that fostering greater cultural understanding will result in better management of environmental issues in the long term. It is possible that in the future, environmental challenges will become sufficiently urgent that the organization will have to pursue innovative alternatives to air travel or that economic challenges will require service innovations that would limit their social impact in the short term. The key to the dynamic equilibrium model is that these short-term "splitting" strategies are in the service of a long-term "equilibrium" strategy (Smith and Lewis 2011), such that all three goals (social, environmental, and economic) are pursued simultaneously when viewed over time.

While our case data suggest that this dynamic equilibrium strategy might be an effective response to paradoxical tensions, the cross-sectional nature of our study prevents us from observing this strategy in action. Future research is needed to explore the mechanics of this approach as well as its effectiveness; it has been minimally explored in prior research (Jay 2013). Studies in this area should employ longitudinal methodologies, and such studies may lend themselves to transformative collaboration among practitioners, academics, and/or policy makers, as in participatory action research (Jay 2013; Ozanne and Saatcioglu 2008). Future research could identify the organizational capabilities required by the dynamic equilibrium strategy, as with the construct of organizational ambidexterity (Raisch and Birkinshaw 2008), and research could observe whether the dynamic equilibrium strategy results in better long-term triple-bottom-line performance, as we predict. Future research could also explore the characteristics of marketing managers and organizational structures that are best able to cope in such paradoxical organizational environments created by firms pursuing the triple bottom line, as well as how marketing managers most effectively balance multiple identities of the triple bottom line in strategic decision making related to (re)positioning, branding, and internal and external communication. Organizational research could investigate how the three elements of the triple bottom line mutually constitute each other, as suggested by Smith, Gonin, and Besharov (2013). For instance, the Sustainability Trust is able to use its successes in the social arena, which provides legitimacy when it markets itself to socially concerned fee-paying clients. Also, the revenues earned from these clients contribute to the Trust's ability to undertake its social and environmental missions. Finally, as the Trust competes against for-profit firms, this has kept them "sharp and on their toes," as explained by a company representative, and better able to provide their services.

Further research is needed to explore the policy conditions that empower a dynamic equilibrium among triple-bottomline objectives. Our findings suggest that the role of policy is not limited to making tensions more salient; policy itself can facilitate dynamic equilibrium among triple-bottom-line objectives. For example, in the Growing Power case, a context of abundance was achieved through a relaxation of local zoning laws to enable urban agriculture. Similarly, conditions of certainty were needed within the Whale Watch Kaikoura case to meet their triple-bottom-line objectives. Direct support from New Zealand laws and protection from competitive pressures enabled economic, social, and environmental goals to be achieved. This analysis opens up future research questions regarding an examination of whether triple-bottom-line objectives are best met through enabling abundance, providing certainty, or facilitating stability.

In conclusion, this analysis provides several important contributions. By identifying the paradoxical tensions at the intersection of the triple bottom line and the important role played by policy context in accentuating these tensions, our hope is that this study will help organizations and policy makers work together to facilitate organizational responses that enhance the ability of firms to achieve long-term sustainability in terms of people, planet, and profits.

\section{References}

Andriopoulos, Constantine and Marianne W. Lewis (2009), "Exploitation-Exploration Tensions and Organizational Ambidexterity: Managing Paradoxes of Innovation," Organization Science, 20 (4), 696-717.

Angus-Leppan, Tamsin, Suzanne Benn, and Louise Young (2010), "A Sensemaking Approach to Trade-Offs and Synergies Between Human and Ecological Elements of Corporate Sustainability," Business Strategy and the Environment, 19 (4), 230-44.

Arnould, Eric J., Alejandro Plastina, and Dwayne Ball (2009), “Does Fair Trade Deliver on Its Core Value Proposition? Effects on Income, Educational Attainment, and Health in Three Countries," Journal of Public Policy \& Marketing, 28 (Fall), 186-201.

Bansal, Pratima (2005), "Evolving Sustainably: A Longitudinal Study of Corporate Sustainable Development," Strategic Management Journal, 26 (3), 197-218.

Bridges, Simon (2013), “\$100 Million for Investing in Warmer, Healthier Homes," press release, (May 16), [available at https://www.beehive. govt.nz/release/100m-investing-warmer-healthier-homes].

Chhabra, Esha (2014), "Bite-Sized Payments Go Global: Solar's Next Challenge," Forbes, (August 12), [available at http://www. forbes.com/sites/eshachhabra/2014/08/12/bite-size-paymentsgo-global-solars-next-challenge/\#19d7418173fe].

DeFillippi, Robert (2009), "Dilemmas of Project-Based Media Work: Contexts and Choices," Journal of Media Business Studies, 6 (4), 5-30.

Delmas, Magali and Vered Doctori Blass (2010), "Measuring Corporate Environmental Performance: The Trade-Offs of Sustainability Ratings," Business Strategy and the Environment, 19 (4), 245-60.

Denison, Daniel R., Robert Hooijberg, and Robert E. Quinn (1995), "Paradox and Performance: Toward a Theory of Behavioral 
Complexity in Managerial Leadership," Organization Science, $6(5), 524-40$.

d.light (2016), "Social Impact," (accessed August 19, 2016), [available at http://www.dlight.com/social-impact/].

Eisenhardt, Kathleen M. (1989), "Building Theories from Case Study Research," Academy of Management Review, 14 (4), 532-50.

and Melissa E. Graebner (2007), "Theory Building from Cases: Opportunities and Challenges," Academy of Management Journal, 50 (1), 25-32.

Elkington, John (2004), "Enter the Triple Bottom Line," in The Triple Bottom Line: Does It All Add Up?, Adrian Enriques and Julie Richardson, eds. Abingdon, UK: Earthscan, 1-16.

Farr, Christina (2013), "Want to Make Money \& Change the World? An Idiot's Guide to 'Social Entrepreneurship,"' VentureBeat, (May 24), [available at http://venturebeat.com/2013/05/24/wantto-make-money-change-the-world-an-idiots-guide-to-socialentrepreneurship/].

Gao, Jijun and Pratima Bansal (2013), "Instrumental and Integrative Logics in Business Sustainability," Journal of Business Ethics, 112 (2), 241-55.

Gartry, Laura (2015), "Plan to Tackle Homelessness by Selling Backyard-Sized Cabins," ABC News, (accessed August 19, 2016), [available at http://www.abc.net.au/news/2015-06-18/nationalinitiative-for-street-swags-rolle-out/6556464].

Hahn, Tobias and Frank Figge (2011), "Beyond the Bounded Instrumentality in Current Corporate Sustainability Research: Toward an Inclusive Notion of Profitability," Journal of Business Ethics, 104 (3), 325-45.

_ Offs in Corporate Sustainability: You Can't Have Your Cake and Eat It," Business Strategy and the Environment, 19 (4), 217-29.

_ Jonatan Pinkse, Lutz Preuss, and Frank Figge (2015), "Tensions in Corporate Sustainability: Towards an Integrative Framework," Journal of Business Ethics, 127 (2), 297-316.

Hansmann, Ralph, Harald A. Mieg, and Peter Frischknecht (2012), "Principal Sustainability Components: Empirical Analysis of Synergies Between the Three Pillars of Sustainability," International Journal of Sustainable Development and World Ecology, 19 (5), 451-59.

Hart, Stuart L. (1995), "A Natural-Resource-Based View of the Firm," Academy of Management Review, 20 (4), 986-1014.

Jarzabkowski, Paula, Jane Lê, and Andrew H. Van de Ven (2013), "Responding to Competing Strategic Demands: How Organizing, Belonging, and Performing Paradoxes Coevolve," Strategic Organization, 11 (3), 245-80.

Jay, Jason (2013), "Navigating Paradox as a Mechanism of Change and Innovation in Hybrid Organizations," Academy of Management Journal, 56 (1), 137-59.

Kang, Charles, Frank Germann, and Rajdeep Grewal (2016), "Washing Away Your Sins? Corporate Social Responsibility, Corporate Social Irresponsibility, and Firm Performance," Journal of Marketing, 80 (March), 59-79.

Kiron, David, Nina Kruschwitz, Knut Hannaes, Martin Reeves, Sonja Fuisz-Kehrbach, and Georg Kell (2015), Joining Forces: Collaboration and Leadership for Sustainability, research report, Massachusetts Institute of Technology [available at http:// sloanreview.mit.edu/projects/joining-forces/].

Holger Rubel, Marin Reeves, and Sonja FuiszKehrbach (2013), "Sustainability's Next Frontier: Walking the Talk on the Sustainability Issues That Matter Most," research report, Massachusetts Institute of Technology [available at http:// sloanreview.mit.edu/projects/sustainabilitys-next-frontier/].

Lavelle, Marianne (2015), "D.light Attacks a Big Energy Problem with Small Solar," The Daily Climate, (April 21), [available at http://www.dailyclimate.org/tdc-newsroom/2015/04/climate-changesolutions-solar-dlight-energy].

Lewis, Marianne W. (2000), "Exploring Paradox: Toward a More Comprehensive Guide," Academy of Management Review, 25 (4), 760-76.

Luscher, Lotte S. and Marianne Lewis (2008), "Organizational Change and Managerial Sensemaking: Working Through Paradox," Academy of Management Journal, 51 (2), 221-40.

—, and Amy Ingram (2006), “The Social Construction of Organizational Change Paradoxes," Journal of Organizational Change Management, 19 (4), 491-502.

Macey, Jonathan R. (1991), "An Economic Analysis of the Various Rationales for Making Shareholders the Exclusive Beneficiaries of Corporate Fiduciary Duties,"Stetson Law Review, 21, 23-44.

Margolis, Joshua D. and James P. Walsh (2003), "Misery Loves Companies: Rethinking Social Initiatives by Business," Administrative Science Quarterly, 48 (2), 268-305.

Menguc, Bulent and Lucie K. Ozanne (2005), "Challenges of the 'Green Imperative': A Natural Resource-Based Approach to the Environmental Orientation-Business Performance Relationship," Journal of Business Research, 58 (4), 430-38.

Mish, Jenny and Debra L. Scammon (2010), "Principle-Based Stakeholder Marketing: Insights from Private Triple-Bottom-Line Firms," Journal of Public Policy \& Marketing, 29 (Spring), 12-26.

O'Driscoll, Aidan (2008), "Exploring Paradox in Marketing: Managing Ambiguity Towards Synthesis," Journal of Business and Industrial Marketing, 23 (2), 95-104.

Orlitzky, Marc, Frank L. Schmidt, and Sara L. Rynes (2003), "Corporate Social and Financial Performance: A Meta-Analysis," Organization Studies, 24 (3), 403-41.

Ozanne, Julie L. and Bige Saatcioglu (2008), "Participatory Action Research," Journal of Consumer Research, 35 (3), 423-39.

Parsell, C., A. Jones, and B. Head (2013), "Policies and Programmes to end Homelessness in Australia: Learning from International Practice," International Journal of Social Welfare, 22 (2), 186-94.

Patton, Michael Quinn (1990), Qualitative Evaluation and Research Methods. Atlanta: Sage Publications.

Phipps, Marcus, Lucie K. Ozanne, Michael Luchs, Saroja Subrahmanyan, Sommer Kapitan, Jesse Catlin, et al. (2013), "Understanding the Inherent Complexity of Sustainable Consumption: A Social Cognitive Framework," Journal of Business Research, 66 (8), 1227-34.

Poole, Marshall S. and Andrew H. Van de Ven (1989), "Using Paradox to Build Management and Organization Theories," Academy of Management Review, 14 (4), 562-78.

Porter, Michael and Claas Van der Linde (1995), "Toward a New Conception of the Environment-Competitiveness Relationship," Journal of Economic Perspectives, 9 (4), 97-118.

Press, Melea and Eric J. Arnould (2009), "Constraints on Sustainable Energy Consumption: Market System and Public Policy Challenges and Opportunities," Journal of Public Policy \& Marketing, 28 (Spring), 102-13.

Raisch, Sebastian and Julian Birkinshaw (2008), "Organizational Ambidexterity: Antecedents, Outcomes, and Moderators," Journal of Management, 34 (3), 375-409. 
Salzmann, Oliver, Aileen Ionescu-Somers, and Ulrich Steger (2005), "The Business Case for Corporate Sustainability: Literature Review and Research Options," European Management Journal, 23 (1), 27-36.

Scherer, Andreas Georg, Guido Palazzo, and David Seidl (2013), "Managing Legitimacy in Complex and Heterogeneous Environments: Sustainable Development in a Globalized World," Journal of Management Studies, 50 (2), 259-84.

Scott, Linda, Jerome D. Williams, Stacey Menzel Baker, Jan Brace-Govan, Hilary Downey, Anne-Marie Hakstian, et al. (2011), "Beyond Poverty: Social Justice in a Global Marketplace," Journal of Public Policy \& Marketing, 30 (Spring), $39-46$.

Sen, Sankar and Chitra B. Bhattacharya (2001), "Does Doing Good Always Lead to Doing Better? Consumer Reactions to Corporate Social Responsibility," Journal of Marketing Research, 38 (May), 225-43.

Simpson, Bonnie and Scott K. Radford (2014), "Situational Variables and Sustainability in Multi-Attribute Decision-Making," European Journal of Marketing, 48 (5/6), 1046-69.

Slawinski, Natalie and Pratima Bansal (2015), "Short on Time: Intertemporal Tensions in Business Sustainability," Organization Science, 26 (2), 531-49.

Smith, Wendy K., Andy Binns, and Michael Tushman (2010), "Complex Business Models: Managing Strategic Paradoxes Simultaneously," Long Range Planning, 43 (2), 448-61.

, Michael Gonin, and Marya L. Besharov (2013), "Managing Social-Business Tensions: A Review and Research Agenda for Social Enterprise,” Business Ethics Quarterly, 23 (3), 407-42. and Marianne W. Lewis (2011), "Toward a Theory of Paradox: A Dynamic Equilibrium Model of Organizing," Academy of Management Review, 36 (2), 381-403.

Van der Byl, Connie A. and Natalie Slawinski (2015), "Embracing Tensions in Corporate Sustainability A Review of Research from Win-Wins and Trade-Offs to Paradoxes and Beyond," Organization \& Environment, 28 (1), 54-79.

Van Marrewijk, Marcel (2003), "Concepts and Definitions of CSR and Corporate Sustainability: Between Agency and Communion," Journal of Business Ethics, 44 (2/3), 95-105.

Weerawardena, Jay and Gillian Sullivan Mort (2012), "Competitive Strategy in Socially Entrepreneurial Non-Profit Organizations: Innovation and Differentiation," Journal of Public Policy \& Marketing, 31 (1), 91-101.

World Commission on Environment and Development (1987), Our Common Future, Oxford, UK: Oxford University Press.

World Economic Forum (2016), New Models for Entrepreneurship, report, (accessed June 13, 2016), [available at http://reports. weforum.org/new-models-for-entrepreneurship/executive-summary/].

Wright, Christopher, Daniel Nyberg, and David Grant (2012), "Hippies on the Third Floor': Climate Change, Narrative Identity, and the Micro-Politics of Corporate Environmentalism," Organization Studies, 33 (11), 1451-75.

Yin, Robert K. (2013), Case Study Research: Design and Methods. Newbury Park, CA: Sage Publications.

Zhang, Kun-min and Zong-guo Wen (2008), "Review and Challenges of Policies of Environmental Protection and Sustainable Development in China," Journal of Environmental Management, 88 (4), 1249-61. 
Copyright of Journal of Public Policy \& Marketing is the property of American Marketing Association and its content may not be copied or emailed to multiple sites or posted to a listserv without the copyright holder's express written permission. However, users may print, download, or email articles for individual use. 